
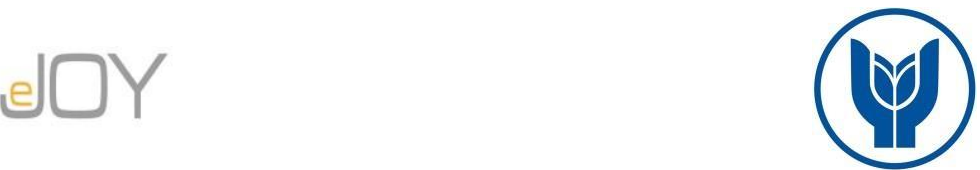

Manavgat, G., Demirci, A. / Journal of Yasar University, 2021, 16/64, 1856-1871

\title{
Lojistik Performans Endeksi Tutarlılığının Sıralı Lojistik Regresyon Modeliyle İncelenmesi
}

\section{Investigation of Consistency of Logistics Performance Index Using Ordered Logistic Regression Model}

\author{
Gökçe MANAVGAT, Toros Üniversitesi, Türkiye gokce.manavgat@toros.edu.tr \\ Orcid No: 0000-0003-3729-835X \\ Ayhan DEMİRCI, Toros Üniversitesi, Türkiye ayhan.demirci@toros.edu.tr \\ Orcid No: 0000-0003-3788-4586
}

\begin{abstract}
$\ddot{O ̈}_{z}: \ddot{U l k e l e r ~ a r a s ı ~ t i c a r e t i n ~ g e l i s ̧ m e s i y l e ~ e t k i n ~ l o j i s t i k ~ f a a l i y e t l e r i n i n ~ r o l u ̈ ~ d e ~ o ̈ n e m l i ~ o ̈ l c ̧ u ̈ d e ~ a r t m ı s ̧ t ı r . ~ A y n ı ~ z a m a n d a, ~}$ güçlü bir lojistik performansı, ticaretin genişlemesi, ihracatın çeşitlenmesi, doğrudan yabancı yatırımları çekme ve ekonomik büyümeye katkı sunmaktadır. Dolayısıla küresel lojistik performansının izlenmesi de ülkelerin rakiplerine göre konumunu değerlendirmeleri için önemli bir araç haline gelmiştir. Bu çalışmada, Dünya Bankası tarafindan yayımlanan Lojistik Performans Endeksi (LPI) verileri kullanılarak ülkelerin lojistik performansını belirleyen değişkenler 2007, 2012 ve 2018 ylları için sıralı (ordered) lojistik regresyon modeliyle belirlenmiştir. Ülkelerin LPI skorları, dış ticaret, taşımacılık ve ekonomik değişkenlerle incelenmiş ve ayrıca bă̆ımsız değişkenlerle arasındaki ilişkiyi belirlemek için çoklu sınıflandırma yöntemi sonuçları da karşılaştırılmuştır Böylece ülkelerin belirtilen (gözlenen) LPI grubunda olması durumu ile modellerden elde edilen (tahmin edilen) gruptaki yerlerinin tutarlılığ belirlenmiştir. Çalışma sonucunda, dış ticaret, milli gelir ve hava taşımacılığına ilişkin değişkenlerin, LPI üzerinde istatistiksel olarak anlamlı ve pozitif etkisinin olduğu tespit edilmiştir. Ayrıca, ülkelerin LPI skorlarına göre gruplandırılması, çalışmada tahmin edilen modellere göre yüksek tutarlılık (yıllara göre değişmekle birlikte, bu oran \%68,2- \%64 aralı̆̆ında) göstermekle birlikte, özellikle yüksek LPI düzeyine sahip grupta yer alan ülkeler için bu durum önemli ölçüde artmaktadır.
\end{abstract}

Anahtar Kelimeler: Lojistik Performans Endeksi (LPI), Lojistik, Siralı Lojistik Regresyon

JEL Sinıflandirmasi: C10, F10, L90

Abstract: With the development of trade between countries, the role of effective logistics activities has increased significantly. At the same time, the strong logistics performance contributes to the expansion of trade, diversification of exports, attracting foreign direct investments and economic growth. Therefore, monitoring the global logistics performance has become a crucial tool for countries to evaluate their position relative to their competitors. In this study, using the Logistics Performance Index (LPI) data published by the World Bank, the variables that determine the logistics performance of the countries were by ordered logistic regression model for the 2007, 2012 and 2018. The LPI scores of the countries were examined with foreign trade, transportation, and economic variables, and also the results of the multiple classification method were compared to determine the relationship between the independent variables. Thus, the consistency between countries in the specified (observed) LPI group and their place in the (estimated) group obtained from the models was determined. In the result of the study, it was determined that the variables related to foreign trade, national income and air transportation have a statistically significant and positive effect on LPI. In addition, although the grouping of countries according to LPI scores shows high consistency according to the model estimations (this ratio varies by years, this ratio is in the range of $68.2 \%-64 \%$ ), this situation increases significantly especially for the countries in the group with high LPI levels.

Keywords: Logistics Performance Index (LPI), Logistics, Ordered Logistic Regression

JEL Classification : C10, F10, L90

\section{Giriş}

Lojistik; ulaşımdan, depolamaya, kargo konsolidasyonuna, sınır kontrollerinden ülke içi dağıtıma ve ödeme sistemlerine kadar uzanan çeşitli kamu ve özel sektör kurumlarını içeren Makale Gecmiși / Article History 
temel faaliyetleri kapsamaktadır (Gümrük Bakanlığı, 2010: 5). Lojistik pek çok sektörün önemli faaliyet ve maliyet alanlarından biridir. $\mathrm{Bu}$ nedenle pek çok ülkenin büyüme ve kalkınma politika hedeflerinden biri de lojistik performansının geliştirilmesidir.

Ülkelerin lojistik faaliyetleri ile uluslararası ticaret süreçleri ve dolayısıyla gelirleri arasında sıkı bir ilişki olduğu belirtilmektedir. Bu açıdan, lojistiğin ekonomik faaliyetler üzerinde pek çok etkisi vardır. Ayrıca, lojistikte üstün performans gösteren ülkelerin kalıcı reform ve gelişmelere yatırım yapan ülkeler olduğu da gözlenmektedir (Shepherd, 2011: 11-12). Bu bağlamda güçlü bir lojistik performansı, ticaretin genişlemesi ve çeşitlenmesine, doğrudan yabancı yatırımları çekme başarısı ve ekonomik büyümeye katkı sunmaktadır.

Son yıllarda literatürde sıklıkla yer alan "ticaretin kolaylaştırılması" ifadesi Dünya Ticaret Örgütü (WTO) tarafindan; "uluslararası ticaret prosedürlerinin basitleştirilmesi ve uyumlaştırılması" şeklinde tanımlanmıştır ve "uluslararası mal ticaretinde gerekli bilgileri toplamak ve işlemek için gerekli faaliyetler ve uygulamalar" bu kapsam içerisinde değerlendirilmektedir. Başka birçok tanım yapılmış olmakla birlikte, dış ticaret için özellikle vurgulanan husus; ticaretin kolaylaştırılmasında ticaret ortamının kalitesi ve ticaret faaliyetlerinin kolay bir şekilde yönlendirilmesi üzerindeki etkisine bağlı olduğu yönündedir. $\mathrm{Bu}$ durum, lojistik sektörünün önemine ve performansına vurgu yapmakta ve ticareti kolaylaştırma ve lojistik arasındaki yakın ilişkiyi de öne çıkarmaktadır (Puertas vd., 2014: 468). Küreselleşme sürecinde özellikle rekabet gücü açısından ülkelerin fayda elde etmeleri için çok yönlü lojistik operasyonlar ve performans temelli stratejiler belirlemeleri gerekmektedir (Faria vd., 2015: 216).

Uluslararası mal ticaretinde, uluslararası tedarik zinciri yapılanması aynı zamanda giderek küreselleşen lojistik faaliyetlere de dönüşmüştür. Çünkü dışa açılan ekonomilerde uluslararası ticarette, ürünlerin taşınması ve depolanması için lojistik faaliyetler vazgeçilmezdir. Yüksek lojistik maliyetler ve düşük hizmet kalitesi, uluslararası ticaret ve ekonomik büyümenin de önündeki önemli engeller olarak kabul edilebilir. Bu açıdan, ülkelerin uluslararası ticarette etkin lojistik faaliyetlerini genişletmesi, hem ülkelerin lojistik rekabet avantajlarını tamına hem de ulusal lojistik strateji planlarının başarısı için önemlidir.

Küresel ölçekte, ülkelerin uluslararası ticaret ve lojistik süreçlerinde karşılaşılan zorlukların ve firsatların tespit edilmesi için takip edilen önemli bir ölçü de Dünya Bankası tarafından yayımlanan Lojistik Performans Endeksi (LPI)'dir. Endeks, ülkelerin lojistik performansının; gümrük, altyapı, uluslararası sevkiyatlar, lojistik kalite ve yeterlilik, izleme ve takip ve zamanlılık olmak üzere 6 ana fonksiyon alanında izlenmesine olanak sağlamaktadır. Farklı boyutla ele alınan ve sektör profesyonellerinin görüşleri kapsamında skorlanan bu endeks 
yaklaşımı, ülkelerin lojistik ve dış ticarette olan üstünlüklerini karşılaştırmak için de önemli bilgiler sunmaktadır.

Literatürde ülkelerin lojistik performanslarını ele alan ve farklı yöntemlerin kullanıldığı çok çeşitli çalışma vardır. Bu çalışmalarda, lojistik performansının ekonomik büyüme ve ihracat üzerine olumlu etkisi olduğunu gösteren bulguların ağırlıkta olduğu gözlenmektedir. Sturm vd., (1999) çalışmalarında lojistik altyapı yatırımlarının ekonomik büyümeyi artırdığını göstermişlerdir. Boopen (2006) yaptığı çalışmasında, ülke gruplarının taşımacılık alt yapısının ekonomik büyüme üzerinde olumlu etkisi olduğunu saptamıştır. Benzer bazı çalışmalar da bu bulguları desteklemekte ve uluslararası alanda lojistik ve ulaşım altyapısının, kurumsal kalitenin, düşük taşıma maliyetlerinin, ticareti kolaylaştırarak ihracat performansına ve ekonomik büyümeye katkı sağladığını göstermektedir (Limão ve Venables, 2001; Levchenko, 2004; Djankov, vd. 2006; Portekiz-Perez ve Wilson, 2010; Korinek ve Sourdin, 2011; Hayaloğlu, 2015; Jhawar ve Garg; 2018). Diğer taraftan ampirik literatürde, lojistik performans endeksi ve alt bileşenlerini ele alıp ülkelerin lojistik süreçlerini yeniden değerlendiren farklı boyutsal çalışmalar da mevcuttur. Erkan (2014), Küresel Rekabet Gücü Endeks ve alt bileşenlerinin LPI üzerindeki etkisini araştırmıştır. Çalışmada Küresel Rekabet Gücü Endeks alt bileşenlerinden teknolojik altyapı ve pazar büyüklüğünün LPI üzerinde etkisi olduğu sonucuna ulaşmıştır. Çakır (2017), OECD ülkelerinin lojistik performansları için yeni bir karma metodoloji ölçüm yönetimi önermişler ve yeni yöntemle belirsizlikleri de modele dahil edilerek daha sağlıklı bir performans ölçümünün sağlanabileceğini ifade etmiştir. Kısa ve Ayçin (2019), OECD ülkelerinin lojistik performans endeksini yeniden ele alarak lojistik performans kriterlerinin önem ağırlıklarını çok kriterli karar yöntemiyle hesaplanmışlar ve ülkelerin lojistik performanslarını sıralamışlardır. Eygü ve Kılınç (2020), Lojistik Performans Endeksi (LPI) istatistiklerine dayalı olarak OECD ülkeleri için yaptıkları analizde, Ridge regresyon yöntemini uygulanmışlar ve genel LPI puanı ile gümrük, altyapı, uluslararası taşımacılık, lojistik yeterliliği ve kalitesi ile zamanlılık değişkenleri arasında anlamlı bir ilişki olduğunu belirlemişlerdir.

Bu çalışmada, ülkelerin Lojistik Performans Endeksi (LPI) sıralamasına etki edebilecek, dış ticaret, taşımacılık ve ekonomik ölçekte makro faktörler sıralı (ordered) lojistik regresyon modeliyle belirlenmiş ve aynı zamanda ülkelerin lojistik performanslarını belirleyen bu açıklayıcı değişkenlere göre endeksin sınıflandırma başarısı da belirlenmiştir. Başka bir ifadeyle, ülkelerin LPI skoru sıralamasına etki edebilecek bağımsız değişkenler ışı̆̆ında endeks skorunun grup/sınıf tutarlılığı tespit edilmiştir. Çalışmada; 2007, 2012 ve 2018 LPI verileri kullanılmış ve her bir yıl için analizler ayrı ayrı gerçekleştirilmiştir. Böylece yıllara göre 
ülkelerin lojistik performansına etki eden göstergelerin etkisi belirlenmiş ve aynı zamanda ülkenin grup ya da sınıfiyla ne ölçüde benzerlik gösterdiği de tespit edilmiştir. Bu bağlamda, çalışmanın önemli bir katkısı, literatürdeki yöntemlerden farklı bir yöntem kullanılarak ülkelerin LPI skorları, dış ticaret, taşımacılık ve ekonomik değişkenlerle incelenmesi ve endeksin geçerlilik araştırmasının yapılmış olmasıdır.

Çalışmada, giriş bölümünü takip eden ikinci bölümde Lojistik Performans Endeksi ve alt bileşenleri açıklanmış, üçüncü bölümde yöntem ve veri seti ortaya konulmuş, dördüncü bölümde analiz ve model tahmin sonuçları sunulmuş ve son olarak çalışmanın genel sonuçları üzerinde durulmuştur.

\section{Lojistik Performans Endeksi ve Bileşenleri}

Bir ülkenin ticari rekabet gücü için kritik bir dizi politikayı içeren en önemli iki bileşen ticaret ve lojistiktir. Zira ülkelerin gelişmişlik düzeylerinin en önemli belirleyicileri arasından önemli bir yer tutan uluslararası ticaret ve bununla doğrudan ilişkili olan lojistik altyapı gücüdür. Zaten lojistik altyapısı güçlü olmayan bir ülkenin uluslararası ticaret yönünden ve dolayısıyla ekonomik açıdan güçlü olmasını beklemek mümkün değildir. En öngörülebilir, verimli ve en iyi yönetilen ulaşım yollarına ve ticaret prosedürlerine sahip ülkelerin, ayrıca teknolojik avantajlardan, ekonomik serbestleşmeden ve uluslararası pazarlara erişimden en iyi şekilde yararlandıkları da bir gerçektir.

Günümüzde uluslararası ticaret; taşınan malların özelliklerinden dolayı gerekli olan depolama, muhafaza etme ve diğer katma değerli hizmetleri kolaylaştıran tüm süreçlerin, bağlantılar aracılığıyla organize ve senkronize edilmesini gerektirmektedir. Mevcut terminaller, bölgesel ve uzun mesafeli bağlantılar ve altyapı (limanların ve havalimanlarının genişletilmesi ve modernizasyonu ile bu düğümlere daha geniş erişim yolları) ve altyapı elemanları ele alındığında, bu konuda oldukça önemli aşamalar kaydedildiği gözlenmektedir. Bunun yanı sıra lojistik platformlar ve dağıtım merkezleri, intermodalite bileşenleri olan arz/talep ve optimum yerler dikkate alınarak konumlandırılmıştır. Tüm bu gelişmeler, mal ticaretini büyük ölçüde kolaylaştırmış ve aynı zamanda maliyetlerde önemli bir düşüşe yol açmıştır (Puertas vd., 2014: 468).

Ülkelerarası rekabette gerek firmaların gerekse kurumların rekabetteki yerlerinin belirlenmesinde ticaret ve lojistik performansın ölçülmesi önemli hale gelmiştir (Bozkurt ve Mermertaş, 2019: 109). 2005 yılına kadar ülkelerin, lojistik performanslarının karşılaştırılması ve ticaretin önündeki engelleri belirlemek için yeterli bilgiye ulaşılamamıştır. Bu kapsamda, ilk olarak 2007 yılında, daha sonra 2010 yılı ve takip eden her iki yılda bir Dünya Bankası 
tarafindan düzenli olarak yayınlanan Lojistik Performans Endeksi (LPI), bu iki bileşen arasındaki ilişkiyi açıklayan önemli bir araç olmuştur. LPI, ülkelerin ulusal lojistik süreçlerinde daha güçlü performans göstermelerini sağlamak için ticaret ortakları ülkelerle karşılaştıkları zorlukları anlamaya yardımcı olmaktadır (Martí vd., 2014: 2984).

$\mathrm{Bu}$ açıdan LPI, ülkelerin lojistik performansında karşılaştıkları zorlukları ve fırsatları belirlemesi için oluşturulmuş karşılaştırılmalı bir endekstir. Dünya Bankası LPI, ülkelerin performansını; gümrük, altyapı, uluslararası sevkiyatların kolaylığı, lojistik altyapı kalite yeterliliği; izleme ve takip ve zamanlılık olmak üzere altı boyut üzerinde ele alınmaktadır (Dünya Bankas1, 2014).

Endeks, tüm ülkeler için ikili ticaretle ve mevcut tesislerle ilgili lojistik gereksinimleri belirlemeleri için uyumlu bir ölçek oluşturarak önemli bir istatistiksel katkı sağlamaktadır. Bu açıdan endeks konuyla ilgili farkındalığın artmasına ve reform için önceliklerin belirlenmesine, kamu-özel diyaloğunun güçlendirilmesine ve farklı ülkelerde ticaret ve taşımacılığın teşvik edilmesine yardımcı olmaktadır. LPI, dünya ticaretinde önemli derecede yetki sahibi ve malların taşınmasında ve küresel ticaretin iyileştirilmesinde söz sahibi olan şirketler üzerinde gerçekleştirilen dünya çapında bir ankete dayanılarak tespit edilmektedir. Lojistik sektörünün farklı faaliyet alanlarında yer alan 800'den fazla profesyonelin kapsamlı görüşlerinin bir ölçüsüdür (Martí vd., 2014: 2984).

LPI hesaplamalarında; sadece 2007 yılı endeksinin hesaplamasında yer verilen ve daha sonra hesaplamalarda kullanılmayan "Yurtiçi lojistik maliyetler" dişında 6 alt bileşen bulunmaktadır. Bunların hiçbiri tek başına iyi bir lojistik performans seviyesinin belirlenmesini garanti etmez. Bu bileşenler ve detayları şu şekilde ifade edilebilir (Yapraklı ve Ünalan, 2017):

Gümrük ve sınır yönetiminin verimliliği: Gümrük dairelerinin hızı, basitliği ve öngörülebilirliği çerçevesinde, gümrük sevkiyat prosedürünün verimliliğinin ve etkinliğinin ölçüldüğü bu alt bileşen, mevcut ticaret mevzuatının uygulanması ve mal ve hizmetlere ilişkin ithalat/ihracat vergilerinin toplanmasıyla ilgili çeşitli idari prosedürlere dayanmaktadır.

Ticaret ve ulaştırma altyapısının kalitesi: Ülkenin ulaşım ve telekomünikasyon altyapısının kalitesini ölçer. Malların nihai tüketiciye taşınmasında kullanılan prosedürlerle ilgilidir ve dış etkenler nedeniyle tamamen şirketler tarafından kontrol edilmemektedir. Bununla birlikte, organizasyonların mevcut tesislerle nasıl başa çıktıklarını ölçmek önemlidir, zira bu durum onları rekabet açısından bir avantaj veya dezavantaja sokacaktır.

Rekabetçi sevkiyat fiyatlarının ayarlanabilmesi kolaylığı: Gönderileri rekabetçi fiyatlarla düzenlemenin ne kadar kolay olduğunu ölçer. 
Lojistik hizmetlerinin kalitesi ve yeterliliği: Lojistik hizmetlerin yeterliliğini ve kalitesini ölçer. Organizasyon yapısı içindeki belirli tarafların nasıl davrandığını, müşteriye hizmet kalitesini temsil ettiğini ve kuruluşlar ile tüketiciler arasındaki ilişkiyi ne şekilde optimize ettiğini gösterir.

Sevkiyatların izlenme ve takip edilebilirliği: Gönderilerin izlenmesini ve takip edilebilirliğini ölçer. Son müşteriye teslim edilmesine kadar her sevkiyatın tam yerini anlık olarak izlemek ve rotasını belirlemek önemlidir. Tedarik zincirindeki tüm taraflar bu bileşene dahil olur ve dolayısıyla izlenebilirlik, sektörün bir bütün olarak faaliyetinin sonucudur.

Sevkiyatların alıcılara beklenen sürelerde ulaştırılma sıklı̆̆ı: Sevkiyat teslimat sürelerini ölçer. Bu boyut dikkate alınması gereken önemli bir diğer faktördür, çünkü mevcut yüksek rekabet koşullarında teslimat programlarına uyulmaması kabul edilemez. Bu durum, giderek daha karmaşık hale gelen dijitalleşme süreçlerine duyulan ihtiyacı etkilemiştir.

$\mathrm{Bu}$ bileşenler, lojistik süreçlerde mesafe ve nakliye maliyetlerinden daha büyük bir etkiye sahip olan ve LPI'yi tanımlayan çeşitli alanları kapsamaktadır. Bu alanlar spesifik olarak; süreçlerin şeffaflığı ve kalitesi ile hizmetlerin öngörülebilirliği ve güvenilirliği gibi temel lojistik değeri olan unsurları içerirler. Endeksin hesaplanmasında ankete katılanlar tarafindan tüm kriterlerin 1 (en kötü) ve 5 (en iyi) arasında puanlanması sağlanmaktadır. Hesaplamalar sonucunda en üst sıralarda yer alan ülkelerin, büyük dağıtım platformlarına ve lojistik hizmetlerinde uzmanlaşmış endüstrilere sahip olduğu gözlenmektedir. Aynı zamanda bu ülkeler, ölçek ekonomilerinden yararlanma eğilimindedirler ve büyük teknolojik yenilikleri yaygın olarak kullanmaktadırlar. Yelpazenin diğer ucunda ise düşük gelirli ülkeler yer almaktadır. Bunlar genellikle, denize kıyısı olmayan veya coğrafi olarak karayla çevrili ya da istikrarsızlık ve çatışmalardan yoğun olarak etkilenen ülkelerdir.

LPI uzmanlara gerçekleştirilen kapsamlı görüşmelerin bir sonucu olarak ülkelerin lojistik performansı hakkında önemli ve karşılaştırmalı bilgiler sunmaktadır. Ancak bazı durumlarda, LPI'nin ülkelerin iyi bir lojistik performans düzeyine sahip olup olmadığı yönünde bağımsız olarak bir değerlendirme sunmadaki başarısı da tartışılmaktadır (Martí vd., 2014). Bunun için LPI ilişkin değerlendirmelerin ampirik olarak da desteklenmesi önemlidir. Bu bağlamda, çalışma, LPI düzeyini makro değişkenlerle yeniden ele alarak ülkelerin LPI düzeyine göre grup sınıfının doğruluğunu kanıtlamaya yönelik ampirik katkılar sunmaktadır. 


\section{Yöntem ve Veri Seti}

\subsection{Siralı (Ordered) Lojistik Regresyon}

Bağımlı değişken kategorilerinin ikiden fazla olması durumunda sıralı (ordered) olasılık modellerinden biri olan logit model kullanılmaktadır. Başka bir ifadeyle, sıralı lojistik regresyon modeli bağımlı değişkenin en az üç kategoriden oluştuğu ve sıralı ölçekte ölçüldüğü durumlarda kullanılmaktadır.

Sıralı lojistik regresyon modelinin temel özellikleri ve varsayımları ise şöyledir (Chen ve Hughes, 2004, akt. Yakut vd. (2015): 174):

- Kategorik ve sıralı olarak ölçülmüş bağımlı-çıktı değişkeni, gözlenmemiş sürekli gizli (latent) bir değişkenden tekrar düzenlenebilir bir değişkendir. Ancak bu sıralı bağımlıçıktı değişkeninin kategorileri arasındaki mesafenin eşit olup olmadığı belirgin değildir.

- Modelde, normallik ve sabit varyans varsayımının sağlanması gerekmediğinden, bağımsız değişkenlerin sıralı kategorik değişkenler üzerindeki etkilerini açıklamak için bir bağlantı fonksiyonu kullanılır.

- Sıralı lojistik regresyon modeli, regresyon katsayılarının değeri kategorik çıktı değişkeninin kategorilerine bağlı olmadığı için açıklayıcı değişkenler ile sıralı kategorik çıktı değişkeni arasındaki ilişkinin kategorilerden bağımsız olduğunu varsayar.

- Ayrıca sıralı lojistik regresyon analizinde normallik, süreklilik, eşvaryanslılık ve çok değişkenli normallik gibi varsayımların sağlanması zorunluluğu olmadığı için model yapısında çeşitli bağlantı fonksiyonlarının kullanılması gerekmektedir. Çünkü bağlantı fonksiyonları, sıralı lojistik regresyon modellerini güçlü bir paralel eğriler varsayımı altında oluşturmaktadır. Sıralı lojistik regresyon analizinde bir modelin kurulabilmesi için paralel eğriler varsayımının sağlanması şartı bulunmaktadır (Eygü ve Kılınç, 2020a: 3598).

Eşitlik 1'deki gizli (latent) değişken yaklaşımıyla oluşturulan kategorik bağımlı Y değişkeninin altında sürekli ve aslında gözlenemeyen rastgele bir $\mathrm{Y}^{*}$ gizli değişkene bağlı olduğunu göstermektedir.

$$
Y^{*}=\sum_{k=1}^{K} \widehat{b_{k}} X_{k}+\varepsilon
$$

$Y^{*}$ bağımlı değişkeni gözlenemez ve gözlenen olayın gizli (latent) eğilimi olarak düşünülür. Hata terimi $\varepsilon$ 'nun normal ya da lojistik ortalama ile belirli simetrik bir dağılım gösterdiği varsayılır. Bağımlı değişkenin J tane sıralı kategoriden oluştuğu değerlendirilirse, gözlenen düzeylerle eğilimler arasındaki ilişki Eşitlik 2'de gösterilmiştir (Akkuş ve Özkoç, 2016). 


$$
\begin{array}{rrr}
Y_{i}=1, & Y^{*} \leq \mu_{1}(=0) \\
Y_{i}=2, & \mu_{1}<Y^{*} \leq \mu_{2} \\
Y_{i}=3, & \mu_{2}<Y^{*} \leq \mu_{3} \quad i=1,2,3 \ldots N \\
Y_{i}=J, & \mu_{J-1}<Y^{*}
\end{array}
$$

Eşitlik 2'deki $\mu$ 'ler yan yana olan kategorileri ayıran bilinmeyen eşik (threshold) parametrelerdir. Genel olarak sıralı kategorilere sahip olan bağımlı değişken modelleri için olasılıklar gizli değişken yaklaşımı kullanılarak Eşitlik 3'teki gibi ifade edilir.

$$
P(y=j)=F\left[\mu_{j}-\sum_{k=1}^{K} \widehat{b_{k}} X_{k}\right]-F\left[\mu_{j-1}-\sum_{k=1}^{K} \widehat{b_{k}} X_{k}\right]
$$

Eşitlik 3 Gözlenen y’nin j. kategoriye dönüşmesi olasılığını vermektedir. $\mu$ ve $\beta$ 'lar sıralı lojistik regresyonla tahmin edilmektedir. Sıralı logit modelde, L logit dağılım fonksiyonunu göstermek üzere, gözlemlerin bağımlı değişkenin kategorilerine düşme olasılıkları Eşitlik 4'de verilmiştir. Burada bağımlı değişkenin üç kategorili sıralı bir değişken olduğu durum gösterilmiştir (Akkuş ve Özkoç, 2016: 132).

$$
\begin{gathered}
P=\left(Y_{i}=1\right)=P\left(Y^{*} \leq 0\right)=P\left(\sum_{k=1}^{K} \widehat{b_{k}} X_{\mathrm{i} k}+\varepsilon_{i} \leq 0\right)=P\left(\varepsilon_{i}\right. \\
\left.\leq-\sum_{k=1}^{K} \widehat{b_{k}} X_{\mathrm{I} k}\right)=F\left[-\sum_{k=1}^{K} \widehat{b_{k}} X_{i k}\right. \\
P=\left(Y_{i}=2\right)=P\left(\mu_{1} \leq Y^{*} \leq \mu_{2}\right)=P\left(0 \leq \sum_{k=1}^{K} \widehat{b_{k}} X_{\mathrm{i} k}+\varepsilon_{i} \leq \mu_{2}\right)=P\left(\sum_{k=1}^{K} \widehat{b_{k}} X_{i k} \leq \varepsilon_{i}\right. \\
\left.\leq \mu_{2}-\sum_{k=1}^{K} \widehat{b_{k}} X_{\mathrm{I} k}\right)=F\left[\mu_{2}-\sum_{k=1}^{K} \widehat{b_{k}} X_{i k}\right]-F\left[-\sum_{k=1}^{K} \widehat{b_{k}} X_{i k}\right. \\
P=\left(Y_{i}=3\right)=P\left(Y^{*} \geq \mu_{2}\right)=P\left(\sum_{k=1}^{K} \widehat{b_{k}} X_{\mathrm{I} k}+\varepsilon_{i} \geq \mu_{2}\right)=P\left(\mu_{2}-\sum_{k=1}^{K} \widehat{b_{k}} X_{i k} \leq \varepsilon_{i}\right)=P\left(\varepsilon_{i}\right. \\
\left.\geq \mu_{2}-\sum_{k=1}^{K} \widehat{b_{k}} X_{\mathrm{i} k}\right)=1-P\left(\varepsilon_{\mathrm{i}} \leq \mu_{2}-\sum_{k=1}^{K} \widehat{b_{k}} X_{i k}\right)=1-F\left[\mu_{2}-\sum_{k=1}^{K} \widehat{b_{k}} X_{i k}\right.
\end{gathered}
$$

Eşitlik 4'te tüm olasıların pozitif olabilmesi için $\mu_{1}<\mu_{2}<\mu_{3} \ldots \ldots<\mu_{j-1}$ kısıtının sağlanması gerekir. J kategorili bir bağımlı değişkeni için gizli değişken $\mathrm{Y}^{*}$ '1n J tane alan olacak biçimde bölünmesi için J-1 tane eşik parametresine ihtiyaç duymaktadır. Bu bağlamda, sıralı lojistik modelinin geçerliliği için paralel eğimler varsayımı önemlidir. Bu varsayıma göre bağımsız değişkenler ile bağımlı değişken arasındaki ilişki bağımlı değişkenin kategorilerine göre değişiklik göstermez ve parametre tahminleri birbirinden farklı eşik değerlerine göre değişmez. Dolayısıyla eğer J kategorili bağımlı değişken bulunuyorsa, “ $\beta_{\mathrm{k}}$ ” parametreleri bir 
tanedir. Bununla birlikte J-1 logit karşılaştırması için $\theta_{\mathrm{j}-1}$ kesme noktası (eşik değeri) yer almaktadir (Yakut vd, 2015: 175-176).

Ayrıca Sıralı Lojistik Regresyon modelin önemli varsayımlarından biri de paralel eğimlerdir. Buna göre bağımlı değişken için değişken değerlerini farklı kategorilere bağlayan katsayıların tüm kategoriler boyunca aynı olması gereklidir. J tane düzeye sahip bir bağımlı değişken J-1 tane modelin ayrı ayrı oluşturulmasına gerek kalmadan herhangi bir açıklayıcı değişkenin tüm düzeyleri için aynı parametre tahminlerine sahip olduğu varsayılmaktadır. Paralel eğimler varsayımının test edilmesinde sıfır hipotezi, ilişkili regresyon katsayıları, bağımlı değişkenin tüm kategorilerinde aynı olduğunu göstermektedir. Paralel eğimler varsayımı şartının sağlanması elde edilen sonuçların doğruluğu ve güvenilirliği için önemli bir ön koşuldur (Akkuş ve Özkoç, 2016: 134).

\subsection{Veri seti}

Çalışmada ülkelerin Lojistik Performans Endeksi (LPI) skoruna eden faktörler belirlenmiş ve çoklu sınıflandırma başarısı ölçülmüştür. Bu kapsamda, Dünya Bankası tarafından iki yılda bir yayımlanan LPI verileri ele alınmış, ülkeler LPI skorlarına göre sıralanmış ve üç kategorideki skor aralıklara göre düşük, orta ve yüksek ülke grubu olarak sınıflandırılmıştır. Çalışmada; 2007, 2012 ve 2018 LPI verileri kullanılmış ve her bir yıl için analizler ayrı ayrı gerçekleştirilmiştir. Ayrıca her bir analiz yılında incelenen ülkelerin sayısı ise sırasıyla 79, 92 ve 84'tür. Ülkelerin yıllara göre farklılaşmasının nedeni ise bazı ülkelerin analize konu yıllara ait verilerinin elde edilememesidir. Bu durum aynı zamanda, analizlerin her bir yıl için ayrı ayrı yapılmasına neden olmuştur. Çalışmada ayıca ülkelerin LPI skoruna göre çoklu sınıflandırmadaki tutarlığg, lojistik performansına etki edebilecek 6 faktörle yeniden analiz edilmiştir. Buna göre, çalışmada uygulanan sıralı lojistik regresyon modellinde kullanılan değişkenler ve veri kaynakları ise şöyledir (Tablo 1):

Bağımlı değişken, sıralı lojistik regresyon için ülkeler LPI düzeyine göre sıralanmış ve üç kategorideki skor aralıklara göre sınıflandırılmıştır. Buna göre lojistik performans düzeyi, 1Düşük LPI ,2- Orta LPI, 3-Yüksek LPI olarak kodlanmıştır.

Bağımsız değişkenler ise (X1) Air: Hava taşımacılığı, kayıtlı taşıyıcıların dünya çapında kalkışları, (X2) Cont: Konteyner liman trafiği (TEU: 20 fit-foot- eşdeğer birim), (X3) Exp: Mal ve hizmet ihracatı (\% GSYH), (X4) Imp: Mal ve hizmet ithalatı (\% GSYH), (X5) Kgsyh: Kişi 
başına GSYH (cari ABD doları), (X6) Inv ${ }^{1}$ : Doğrudan yabancı yatırım, net girişler (BoP, cari ABD \$). Bağımsız değişkenlerin tamamı Dünya Bankası resmi internet sitesinden sağlanmıştır.

Tablo 1. Modelde Kullanılan Değişkenler

\begin{tabular}{|c|c|}
\hline Bağımlı değişken (Sıralı Logit) & Kaynak \\
\hline & Dünya Bankası $(2007,2012$ ve \\
\hline 1: Düşük LPI & 2018) \\
\hline 2: Orta LPI & Ülkeler LPI skorlarına göre \\
\hline 3: Yüksek LPI & $\begin{array}{l}\text { sıralanmış ve üç kategorideki skor } \\
\text { aralıklara göre sınıflandırılmıştır. }\end{array}$ \\
\hline Bağımsız değişkenler & Kaynak \\
\hline $\begin{array}{l}\text { Air: Hava taşımacılığı, kayıtlı taşıyıcıların dünya çapında } \\
\text { kalkışları }\end{array}$ & \multirow{6}{*}{$\begin{array}{l}\text { Dünya Bankası }(2007,2012 \text { ve } \\
\text { 2018) }\end{array}$} \\
\hline Cont: Konteyner liman trafiği (TEU: 20 fit-foot- eşdeğer birim) & \\
\hline Exp: Mal ve hizmet ihracatı (\% GSYH) & \\
\hline Imp: Mal ve hizmet ithalatı (\% GSYH) & \\
\hline $\begin{array}{l}\text { Kgsyh: Kişi başına Gayrisafi Yurtiçi Hasıla-GSYH (cari ABD } \\
\text { doları) }\end{array}$ & \\
\hline Inv: Doğrudan yabancı yatırım, net girişler (BoP, cari ABD \$) & \\
\hline
\end{tabular}

\section{Verilerin Analizi ve Tahmin Sonuçları}

\subsection{Model Uygunluğunun Sinanmast}

Sıralı lojistik regresyon modeline ilişkin sonuçlar verilmeden önce model uyum testleri her y1l için yapılmıştır. Öncelikle paralellik varsayımına uygunluğu test edilmiştir. Sonuçlar Tablo 2'de sunulmuştur. Paralel eğimler varsayımı test istatistiği olasılık değerleri 0.05 'ten büyük olduğu için $(\mathrm{p}>0.05)$ paralel eğimler varsayımı testinin sıfır hipotezi $\left(\mathrm{H}_{0}\right)$ reddedilmemiştir. Dolayısıyla regresyon katsayılarının, bağımlı değişkenin bütün kategorileri için aynı olduğu kabul edilmiştir. Buna göre parametre tahminleri aynı kesme noktasından geçmektedir.

Tablo 2. Paralellik Varsayımı Testleri

\begin{tabular}{|c|r|r|r|r|}
\hline $\begin{array}{c}\text { Model } \\
(\mathbf{2 0 0 7})\end{array}$ & $\mathbf{- 2}$ Log Likelihood & $\begin{array}{c}\text { Chi-Square } \\
(\chi 2)\end{array}$ & Sd. & $\begin{array}{c}\text { p. } \\
\text { (Olasılık) }\end{array}$ \\
\hline $\mathrm{H}_{0}$ & 118.599 & & & \\
\hline Genel & 95.409 & 23.189 & 6 & .101 \\
\hline
\end{tabular}

\begin{tabular}{|c|r|r|r|r|}
\hline $\begin{array}{c}\text { Model } \\
(\mathbf{2 0 1 2})\end{array}$ & -2 Log Likelihood & $\begin{array}{c}\text { Chi-Square } \\
(\chi 2)\end{array}$ & Sd. & $\begin{array}{c}\text { p. } \\
(\text { Olasılık) }\end{array}$ \\
\hline $\mathrm{H}_{0}$ & 160.968 & & & \\
\hline Genel & 157.865 & 3.103 & 6 & .796 \\
\hline
\end{tabular}

\begin{tabular}{|c|r|r|r|r|}
\hline $\begin{array}{c}\text { Model } \\
(\mathbf{2 0 1 8})\end{array}$ & $-\mathbf{2}$ Log Likelihood & $\begin{array}{c}\text { Chi-Square } \\
(\chi 2)\end{array}$ & Sd. & $\begin{array}{c}\text { p. } \\
\text { (Olasılık) }\end{array}$ \\
\hline $\mathrm{H}_{0}$ & 133.387 & & & \\
\hline Genel & 124.626 & 8.761 & 5 & .119 \\
\hline
\end{tabular}

\footnotetext{
${ }^{1} \mathrm{Bu}$ veri, 2018 yılı için yapılan analizde her ülke için bulunamadığından bu değişken modele dahil edilememiştir.
} 
Paralellik varsayımın geçerliliği tespit edildikten sonra modelin uyum iyiliği testi için Pearson $\mathrm{R}^{2}$ ve sapma istatistiklerinden yararlanılmış ve sonuçlar Tablo 3 'te verilmiştir. Person ve sapma olasılık değerleri 0.05 'ten büyük ( $>0.05)$ olduğu için sıfır hipotezi $\left(\mathrm{H}_{0}\right)$ reddedilmemiştir. Buna göre, kurulan modelin verilerle uyumlu yani sıralı lojistik regresyon modelinin veri uyumunun yeterli düzeyde ve istatistiksel olarak anlamlı olduğu saptanmıştır. Ayrıca kurulan model için Pseudo $\mathrm{R}^{2}$ değerleri için Cox\& Snell istatistik değerleri hesaplanmıştır. Buna göre, bağımsız değişkenlerin, bağımlı değişkenleri açıklama düzeyinin yeterli olduğu gözlenmiştir.

Tablo 3. Model Uyum İyiliği Testi ve Pseudo $R^{2}$ Dĕgerleri

\begin{tabular}{|c|c|c|c|}
\hline 2007 & Chi-Square $(\chi 2)$ & Sd. & p. (Olasılık) \\
\hline Pearson & 157.670 & 150 & .318 \\
\hline Sapma & 118.599 & 150 & .972 \\
\hline Cox \& Snell & \multicolumn{3}{|c|}{.500} \\
\hline 2012 & Chi-Square $(\chi 2)$ & Sd. & p. (Olasılık) \\
\hline Pearson & 183.726 & 176 & .329 \\
\hline Sapma & 160.968 & 176 & .785 \\
\hline Cox $\&_{2818}$ & \multicolumn{3}{|l|}{ Chi-Square $\left(\chi^{2}\right)$} \\
\hline Pearson & 143.125 & 161 & .841 \\
\hline Sapma & 133.387 & 161 & .945 \\
\hline Cox \& Snell & \multicolumn{3}{|c|}{.456} \\
\hline
\end{tabular}

\subsection{Model Tahmin Sonuçlart}

Ön testler sonucunda çalışmada kullanılan sıralı lojistik regresyon modelinin veri uyumunun yeterli düzeyde olduğu tespit edildikten sonra Lojistik Performans Endeksi bağımsız değişkeni ve bağımlı değişkenler için belirlenen sıralı lojistik regresyon analizine ait sonuçlar Tablo 4'te sunulmuştur. Tabloda her bir yıl için ayrı ayrı yapılan sıralı lojistik regresyon analizi sonuçları yer almaktadır. Tahmin parametreleri sunulurken sıralı lojistik regresyon analizinin $\beta$ katsayıları yerine Odds (göreceli olasılık) oranı değerleri verilmiştir. Böylece bağısız değişkenlerin logit üzerindeki etkisi yorumlanmıştır. Odds oranı 1'den büyük ise bağımsız değişkenin logit'te artırıcı bir etkisi olduğunu, Odds oranı değerinin 1'den küçük olması bağımsız değişkenin logit'te azaltıcı bir etkisi olduğunu ve Odd oranı değerinin 1'e eşit olması bağımsız değişkenin logit’te değişime neden olmadığg ş̧eklinde değerlendirilebilir (O'Connell, 2006). 
Buna göre 2007 yılına ait modelde ülkelerin LPI üzerinde (X4) Imp, mal ve hizmet ithalatı (\% GSYH) ve (X5) Kgsyh, kişi başına GSYH değerinin istatistiksel olarak anlamlı ve pozitif bir ektisi olduğu saptanmıştır. (X4) Imp ve (X5) Kgsyh, değişkenindeki bir birimlik artışın diğer tüm bağımsız değişkenler sabit kalmak şartıyla, düşük ve orta lojistik performans düzeyine karşın, yüksek lojistik performans düzeyinin odds'unda pozitif etkiye (değişken değerinin üstel lojistik değeri yani odds oranları sırasıyla; 24.248 ve 6.620) sahip olduğu görülmektedir. Başka bir deyişle, ithalat ve kişi başına GSYH değerleri yüksek olan ülkelerin, lojistik performans endeksinde yüksek ülke grubunda olma olasılığı anlamlı ölçüde artmaktadır. 2012 yılı için yapılan analizde benzer şekilde (X3) Exp, mal ve hizmet ihracatı (\% GSYH), (X4) Imp, mal ve hizmet ithalatı (\% GSYH) ve (X5) Kgsyh, kişi başına GSYH bağımsız değişkenleri istatistiksel olarak anlamlı ve pozitif bir etkiye sahiptir. (X3) Exp, (X4) Imp ve (X5) Kgsyh, değişkenindeki bir birimlik artışın diğer tüm bağımsız değişkenler sabit kalmak şartıyla, düşük ve orta lojistik performans düzeyine karşın yüksek lojistik performans düzeyinin odds'unda pozitif etkiye (sırasıyla odds oranları, 1.202, 7.968 ve 5.443) sahiptir. 2018 yılı için yapılan analizde ise (X1) Air, hava taşımacılığı, kayıtlı taşıyıcıların dünya çapında kalkışları, (X3) Exp, mal ve hizmet ihracatı (\% GSYH) ve (X5) Kgsyh, kişi başına GSYH değişkenlerinin ülkelerin lojistik performans endeks skorları üzerinde pozitif ve istatistiksel olarak anlamlı olduğu saptanmıştır. (X1) Air, (X3) Exp ve (X5) Kgsyh, değişkenindeki bir birimlik artışın diğer tüm bağımsız değişkenler sabit kalmak şartıyla, düşük ve orta lojistik performans düzeyine karşın yüksek lojistik performans düzeyinin odds'unda pozitif etkiye (sırasıyla odds oranı, 1.706, 1.043 ve 6.266) sahip olduğu görülmektedir. Bu durum, özellikle son dönemde ülkelerin lojistik performansında yüksek başarı göstermesinde hava taşımacılığı, ihracat ve kişi başına milli gelir değişkenlerinin önemli ölçüde katkı sunduğunu göstermektedir. Her üç yıl için yapılan analizlerde (X2) Cont, konteyner liman trafiği (TEU: 20 fit-foot- eşdeğer birim), ve (X6) Inv, doğrudan yabancı yatırım, net girişlerin lojistik performansında istatiksel olarak anlamlı bir etkisi olmadığı belirlenmiştir. 
Tablo 4. Model Tahmin Sonuçları

\begin{tabular}{|c|c|c|c|c|c|c|}
\hline \multirow[b]{2}{*}{ LPI } & \multicolumn{2}{|c|}{2007} & \multicolumn{2}{|c|}{2012} & \multicolumn{2}{|c|}{2018} \\
\hline & $\begin{array}{l}\text { Odd. oranı } \\
\text { (Std.Hata) }\end{array}$ & $\mathbf{P}>|\mathbf{z}|$ & $\begin{array}{l}\text { Odd. oranı } \\
\text { (Std.Hata) }\end{array}$ & {$[\mathbf{P}>|\mathbf{z}|$} & $\begin{array}{l}\text { Odd. oranı } \\
\text { (Std.Hata) }\end{array}$ & $\mathbf{P}>|\mathbf{z}|$ \\
\hline (X1) Air & $\begin{array}{c}2.416 \\
(1.350)\end{array}$ & 0.115 & $\begin{array}{l}1.302 \\
(.315)\end{array}$ & 0.276 & $\begin{array}{l}1.706 \\
(.475)\end{array}$ & 0.055 \\
\hline (X2) Cont & $\begin{array}{l}1.168 \\
(.393)\end{array}$ & 0.645 & $\begin{array}{l}1.302 \\
.282\end{array}$ & 0.223 & $\begin{array}{l}1.364 \\
(.371)\end{array}$ & 0.254 \\
\hline (X3) Exp & $\begin{array}{l}.26265 \\
(.297)\end{array}$ & 0.238 & $\begin{array}{l}1.202 \\
.192\end{array}$ & 0.093 & $\begin{array}{c}1.043 \\
(1.563)\end{array}$ & 0.03 \\
\hline (X4) Imp & $\begin{array}{c}24.480 \\
(30.782)\end{array}$ & 0.011 & $\begin{array}{c}7.968 \\
(7.827)\end{array}$ & 0.035 & $\begin{array}{c}1.732 \\
(2.917)\end{array}$ & 0.33 \\
\hline (X5) Kgsyh & $\begin{array}{c}6.620 \\
(2.397)\end{array}$ & 0.000 & $\begin{array}{c}5.433 \\
(1.711) \\
\end{array}$ & 0.000 & $\begin{array}{c}6.266 \\
(2.399)\end{array}$ & 0.000 \\
\hline (X6) Inv & $\begin{array}{c}.796 \\
(.240)\end{array}$ & 0.451 & $\begin{array}{c}0.378 \\
(0.985)\end{array}$ & 0.564 & - & - \\
\hline /cut1 & & & $\begin{array}{l}22 . \\
(4 .\end{array}$ & & & \\
\hline /cut2 & $\begin{array}{l}33 \\
(6 .\end{array}$ & & $\begin{array}{l}25 . \\
(4 .\end{array}$ & & & \\
\hline Gözlem sayısı & & & & & & \\
\hline LR $\operatorname{chi}^{2}(6)$ & & & & & & \\
\hline Prob $>$ chi $^{2}$ & 0.0 & & 0.0 & & & \\
\hline Pseudo $R^{2}$ & & & & & & \\
\hline
\end{tabular}

*Parantez içindeki değerler standart hataları göstermektedir.

Tablo 5'te sıralı lojistik regresyon analizi 2007,2012 ve 2018 yılları için sırasıyla 79, 92 ve 84 ülke için Lojistik Performans Endeksi (LPI) düzeyi (düşük, orta ve yüksek) sınıflandırma sonuçları gösterilmiştir. Diğer deyişle, LPI skoruna göre ülkelerin lojistik performans düzeyleri ile çalışmada kullanılan modeldeki bağımsız değişkenlerle elde edilen sonuçlara göre ülkelerin benzer sınıflandırmada olma başarısı her bir yıl için ayrı ayrı gösterilmiştir. Tablo 4'e göre LPI skor sınıflandırma, sıralı lojistik regresyon modeliyle analiz edildiğinde, 2007 y1lı için 28 düşük LPI skoruna sahip ülkenin 18'i; 25 orta LPI skoruna sahip ülkenin 12'si ve 26 yüksek LPI skoruna sahip ülkenin 24'ü doğru tahmin edilmiştir, böylece düşük orta ve yüksek düzey ülkeler için ise sırasıyla \%64.3, \%48.0 ve \%92.3'lük doğru sınıflandırma başarısı olduğu tespit edilmiştir. 2007 yılı için tüm ülkelerin toplam sınıflandırma başarısı ise \%68.4'tür. 2012 ve 2018 y1lları için de benzer şekilde yorum yapmak mümkündür. 2012 ve 2018 için analize dahil edilen ülkelerin toplam sınıflandırma başarısı sırasıyla \%62.0 ve \%63.1'dir. Genel olarak, yüksek LPI skoruna sahip ülkelerin çalışmaya dahil edilen açıklayıcı değişskenlere yeniden analiz edildiğinde, aynı grupta yer alma başarısının oldukça yüksek olduğu gözlenmektedir (2007, için \%92.3; 2012 için \%76.7 ve 2008 için \%92.9). Ayrıca, ülkelerin LPI skorlarına göre sınıfları, çalışmada tahmin edilen modellere göre yüksek tutarlılık göstermekle birlikte, 
özellikle yüksek LPI düzeyine sahip grupta yer alan ülkeler için bu durum önemli ölçüde artmaktadır. Yani yüksek LPI'ye sahip ülkeler arasında gözlenen grup ile tahmin edilen grup büyük ölçüde benzeşmektedir.

Tablo 5. Sıralı Lojistik Regresyon Analizi Sınıflandırma Başarısı Sonucu

\begin{tabular}{|c|c|c|c|c|c|}
\hline \multirow{2}{*}{$\begin{array}{c}\text { Gözlenen } \\
\text { Grup }\end{array}$} & $\begin{array}{c}\text { Düşü } \\
\mathrm{k}\end{array}$ & Orta & Yüksek & Toplam & $\begin{array}{c}\text { Doğruluk } \\
\text { Yüzdesi }\end{array}$ \\
\cline { 2 - 6 } & 18 & 8 & 2 & 28 & 64.3 \\
\hline Düşük & 11 & 12 & 2 & 25 & 48.0 \\
\hline Orta & 2 & 0 & 24 & 26 & 92.3 \\
\hline Yüksek & 39.2 & 25.3 & 35.4 & 79 & 68.4 \\
\hline $\begin{array}{c}\text { Genel } \\
\text { Yüzde }\end{array}$ & & & & & \\
\hline
\end{tabular}

\begin{tabular}{|c|c|c|c|c|c|}
\hline \multirow{2}{*}{$\begin{array}{c}\text { Gözlenen } \\
\text { Grup }\end{array}$} & \multicolumn{5}{|c|}{ Tahmin Edilen Grup (2012) } \\
\cline { 2 - 6 } & $\begin{array}{c}\text { Düşü } \\
\text { Düşük }\end{array}$ & Orta & $\begin{array}{c}\text { Yüks } \\
\text { ek }\end{array}$ & Toplam & $\begin{array}{c}\text { Doğruluk } \\
\text { Yüzdesi }\end{array}$ \\
\hline Orta & 19 & 12 & 0 & 31 & 61.3 \\
\hline Yüksek & 4 & 15 & 8 & 31 & 48.4 \\
\hline $\begin{array}{c}\text { Genel } \\
\text { Yüzde }\end{array}$ & 33.7 & 32.6 & 33.7 & 92 & 62.0 \\
\hline
\end{tabular}

\begin{tabular}{|c|c|c|c|c|c|}
\hline \multirow{2}{*}{$\begin{array}{c}\text { Gözlenen } \\
\text { Grup }\end{array}$} & \multicolumn{5}{|c|}{ Tahmin Edilen Grup (2018) } \\
\cline { 2 - 6 } & $\begin{array}{c}\text { Düşü } \\
\mathrm{k}\end{array}$ & Orta & Yüksek & Toplam & $\begin{array}{c}\text { Doğruluk } \\
\text { Yüzdesi }\end{array}$ \\
\hline Düşük & 16 & 12 & 0 & 28 & 57.1 \\
\hline Orta & 10 & 11 & 7 & 28 & 39.3 \\
\hline Yüksek & 1 & 1 & 26 & 28 & 92.9 \\
\hline $\begin{array}{c}\text { Genel } \\
\text { Yüzde }\end{array}$ & 32.1 & 28.6 & 39.3 & 84 & 63.1 \\
\hline
\end{tabular}

\section{Sonuç}

$\mathrm{Bu}$ çalışmada, ülkelerin ticaret lojistik performansının ölçülmesinde ve karşılaştırılmasında kullanılan Lojistik Performans Endeksini (LPI) açıklayan değişkenler, sıralı (ordered) lojistik regresyon analiziyle belirlenmiştir. Ayrıca LPI skoruna etki eden bağımsız değişkenlerle yapılan analiz sonuçlarının, endeks skorunun grup başarısıyla olan tutarlılığı da saptanmıştır. LPI'nin belirlenmesinde, altı bağımsız değişken kullanılmıştır. Bunlar; hava taşımacılığı, kayıtlı taşıyıcıların dünya çapında kalkışları, konteyner liman trafiği (TEU: 20 fit-eşdeğer birim), Mal ve hizmet ihracatı (\% GSYH), Mal ve hizmet ithalatı (\% GSYH), kişi başına GSYH (cari ABD doları) ve doğrudan yabancı yatırım, net girişler (BoP, cari ABD \$)'dir. Sıralı lojistik regresyon analizinin bağımlı değişken kategorisi için ülkelerin LPI skorları üç gruba (düşük, orta ve yüksek LPI) ayrılmıştır. Çalışmada; 2007, 2012 ve 2018 LPI verileri kullanılmış ve her bir yıl için analizler ayrı ayrı gerçekleştirilmiştir. Böylece yıllara göre ülkelerin lojistik performansına etki eden, dış ticaret, taşımacılık ve ekonomik göstergelerin etkisinin lojistik 
performans endeksine göre ülkenin grup ya da sınıfıyla ne ölçüde benzerlik gösterdiği de yıllara göre karşılaştırılmıştır.

Analiz sonuçlarında her yıl için ülkelerin LPI skorunda mal ve hizmet ihracatı ve ithalatı (\% GSYH) ve kişi başına GSYH (cari ABD doları) değişkenlerin istatistiksel olarak anlamlı ve pozitif bir etkisi olduğu belirlenmiştir. Bu durum, ülkelerin yüksek lojistik performans endeksi skoruna sahip olmasında, dış ticaret ve milli gelir büyüklüklerinin önemli olduğu sonucunu ortaya koymaktadır. Bu sonuçlar, literatürdeki benzer çalışmaların sonuçlarıyla da uyumludur (Shepherd, 2011; Puertas vd., 2014; Martí vd., 2014; Faria vd., 2015, Gani, 2017). Çalışmanın önemli sonuçlarından biri de son dönemde (2018) lojistik performansında hava taşımacılığına ilişkin dünya çapında kalkışların istatiksel olarak anlamlı ve pozitif etkisinin olmasıdır. Elde edilen bu bulgu, ülkelerin hava taşımacılığına ilişkin yatırımların artırılmasına yönelik lojistik ve dış ticaret politikaları geliştirmesinin, lojistik performansında üst sıralarda yer almasına katkı sunacağını göstermektedir.

Ayrıca çalışma bağımlı değişkeni 3 kategorili (düşük, orta ve yüksek LPI) sıralı değişkeni ifade ettiğinden, bağımsız değişkenlerle arasındaki ilişkiyi belirlemek için çoklu sınıflandırma yöntemi sonuçları da incelenmiştir. Böylece çalışmada tahin edebilen modele göre ülkelerin LPI grubundaki yerleri ile gerçekteki (gözlenen) LPI grubundaki yerleri karşılaştırılmıştır. Buna göre, ülkelerin LPI skorlarına göre gruplarının/sınıflarının, çalışmada tahmin edilen modellerle benzerliği yüksek olmakla birlikte, özellikle yüksek LPI düzeyine sahip grupta yer alan ülkelerin doğru kategoride yer alma olasılığının arttığı gözlenmiştir. Bir başka deyişle, yüksek LPI skoruna sahip ülkelerin çalışmaya dahil edilen makro ölçekli dış ticaret, taşımacılık ve ekonomik değişkenlerle yeniden analiz edildiğinde, aynı grupta yer alma başarısı oldukça artmaktadir.

Araştırma sonucunda elde edilen sonuçlar dikkate alındığında, bundan sonraki çalışmalarda LPI'yi açıklayacak farklı bağımsız değişkenlere ilişkin verilerin derlenmesi halinde ülkelerin lojistik performanslarının ölçülesinde daha doğru tahminlerin yapılması mümkün olabilir. Ayrıca, gelecek dönemlerde daha geniş bir dönemde analizlerin ele alınması, lojistik performansının incelenmesinde daha doğru politikaların oluşturulmasına ve uygulanmasına yardımcı olabilir. 


\section{KAYNAKÇA}

Akkuş, Ö. \& Özkoç, H. (2016). STATA Uygulamalı ile Nitel Veri Analizi, Seçkin Yayıncılık, Ankara.

Boopen, S. (2006). Transport Infrastructure and Economic Growth: Evidence From Africa Using Dynamic Panel Estimates. The Empirical Economics Letters, 5(1), 37-52.

Bozkurt, C. \& Mermertaş, F (2019). Türkiye ve G8 Ülkelerinin Lojistik Performans Endeksine Göre Karşılaştırılması, İşletme ve İktisat Çalışmaları Dergisi 7(2), 107-117.

Chen, C.K. \& Hughes, J. J. (2004). Using Ordinal Regression Model to Analyse Student Satisfaction Questionnaires. IR Applications, Association for Institutional Research, Vol.1, 1-13.

Çakır, S. (2017). Measuring Logistics Performance of OECD Countries Via Fuzzy Linear Regression. Journal of Multi-Criteria Decision Analysis, (Wiley Research Article), 24 (3-4), 177-186.

Djankov, S., Freund, C. \& Pham, C. S. (2006). Trading on Time [Working Paper $\mathrm{N}^{\circ}$ 3909]. The World Bank Policy Research Working Paper, Washington, D.C., 39.

Erkan, B. (2014). Türkiye'de Lojistik Sektörü ve Rekabet Gücü. ASSAM Uluslararası Hakemli Dergi, 1, 44-65.

Eygü, H. \& Kılınç, A. (2020a). Yaşam Memnuniyeti Üzerinde Etkili Olan Faktörlerin Araştırılması: Kayseri İli Örneği. Uluslararası Toplum Araştırmaları Dergisi. 10(16), 3593-3618.

Eygü, H. \& Kılınç, A. (2020). OECD Ülkelerinin Lojistik Performans Endekslerinin Ridge Regresyon Analizi İle Araştırılması. Trakya Üniversitesi Sosyal Bilimler Dergisi, 22(2) ,899-919.

Faria, R. N. De, Souza, C. S. De, \& Vieira, J. G.V. (2015). Evaluation of Logistic Performance Indexes of Brazil in The International Trade. Ram. Revista De Administração Mackenzie, 16(1), 213-235.

Gani, Azmat (2017). The Logistics Performance Effect in International Trade, The Asian Journal of Shipping and Logistics 33(4), 279-288.

Hayaloğlu, P. (2015). The Impact of Developments in The Logistics Sector on Economic Growth: The Case of OECD Countries. International Journal of Economics and Financial Issues, 5(2), 523-530.

Jhawar, A. \& Garg, S. K. (2018). Modelling of Critical Factors for Improving Logistics Performance of India Using Interpretive Structural Modelling. International Journal of Applied Management Sciences and Engineering, 5(1).

Kısa, A.C.G. \& Ayçin, E. (2019). OECD Ülkelerinin Lojistik Performanslarının SWARA Tabanlı EDAS Yöntemi ile Değerlendirilmesi. Çankırı Karatekin Üniversitesi İ̈BF Dergisi, 9 (1), 301-325.

Korinek, J. \& Sourdin, P. (2011). To What Extent Are High-Quality Logistics Services Trade Facilitating?. OECD Trade Policy Working Papers, No.108, 1-42, OECD Publishing.

Levchenko, A. (2004). Institutional Quality and International Trade [Working Paper $\mathrm{N}^{\mathrm{o}}$ 04/231]. International Monetary Fund. Washington, D.C.

Limão, N., \& Venables, A. J. (2001). Infrastructure, Geographical Disadvantage, Transport Costs and Trade. The World Bank Economic Review, 15(3), 451-479.

Marti, L., Puertas, R. \& Garcia, L. (2014). The Importance of the Logistics Performance Index in International Trade, Applied Economics, Vol. 46, No. 24, 2982-2992.

O'Connell, A.A. (2006). Logistic Regression Models for Ordinal Response Variables. Thousand Oaks, Sage Publications, London.

Portugal-Perez, A. \& Wilson, J. S. (2010). Export Performance and Trade Facilitation Reform: Hard and Soft Infrastructure [Working Paper No 5261]. World Bank Policy Research. Washington, D.C.

Puertas, R., Marti, L. \& Garcia, L. (2014). Logistics Performance and Export Competitiveness: European Experience, Empirica, 41, 467-480.

Shepherd, B., (2011). Logistics Costs and Competitiveness: Measurement and Trade Policy Applications. Transport Research Support Working Paper, World Bank. https://mpra.ub.unimuenchen.de/38254/1/MPRA_paper_38254.pdf

Sturm, J.E., Jacobs, J. ve Groote, P. (1999). Output Effects of Infrastructure Investment in the Netherlands. 18531913. Journal of Macroeconomics, 21(2), 355-380.

T.C. Gümrük ve Ticaret Bakanlı̆̆ı (2012). The Logistics Performance Index 2010, Ankara Yayın No: 113 http://risk.gtb.gov.tr/data/52c5898e487c8eca94a7c695/Lojistik\%20Performans\%20Endeksi\%202010.pd $\mathrm{f}$

Yakut, E., Gündüz, M. \& Demirci, A. (2015). İnsani Kalkınmışlık Düzeyinin Sınıflandırma Başarılarının Karşılaştırılmasında Sıralı Lojistik Regresyon Analizi ve Yapay Sinir Ağları Yöntemlerinin Kullanılması. İşletme Araştırmaları Dergisi. 7(4), 172-199.

Yapraklı, T.Ş. \& Ünalan M. (2017). Küresel Lojistik Performans Endeksi ve Türkiye'nin Son 10 Yıllık Lojistik Performansının Analizi. Atatürk Üniversitesi İktisadi ve İdari Bilimler Dergisi, 31(3), 589-606. 